\title{
ECOSUPPORT: A Pilot Study on Decision Support for Baltic Sea Environmental Management
}

\author{
H. E. Markus Meier, Helén C. Andersson
}

\section{BACKGROUND}

The Baltic Sea is a semi-enclosed sea with limited water exchange with the world ocean and with a freshwater surplus resulting in a brackish water body with strong vertical and horizontal stratifications (e.g., Leppäranta and Myrberg 2009). The discharge of large rivers causes a wide range of sea surface salinities between $2 \mathrm{~g} \mathrm{~kg}^{-1}$ in the north (Bothnian Bay) or east (Gulf of Finland) and $20 \mathrm{~g} \mathrm{~kg}^{-1}$ in the south (Kattegat) (Fig. 1). Also, the vertical gradients of salinity are large. For instance, the vertical salinity gradient in the eastern Gotland Basin amounts to about $4 \mathrm{~g} \mathrm{~kg}^{-1}$. This specific hydrography prevents a sufficient ventilation of the deep water with the consequence of oxygen depletion. In addition to this natural factor, the anthropogenic impact of 85 million people, living in the catchment area of the Baltic Sea, is significant. Inter alia, intensive agriculture and inadequately treated sewage water result in eutrophication, reinforcing oxygen depletion. The latter effect is today so pronounced that large areas of the sea bottom are covered by hypoxia or even anoxia, i.e. by bottom water with a dissolved oxygen concentration below $\sim 2 \mathrm{ml} \mathrm{O}_{2} \mathrm{1}^{-1}$, or completely depleted, respectively (Hansson et al. 2011).

To counteract the consequences of eutrophication, the Baltic Sea Action Plan (BSAP) by the Helsinki Commission (HELCOM) was designed to improve the environmental conditions of the Baltic Sea (Backer et al. 2010). Nutrient load reductions at country level were calculated to fulfil scientifically based environmental targets (Wulff et al. 2007). However, the original figures of the BSAP were estimated without taking climate change into account. To overcome this shortcoming, the ECOSUPPORT project (Advanced modelling tool for scenarios of the Baltic ECOsystem to SUPPORT decision making $^{1}$ ) was initiated to investigate the combined impacts of changing climate and changing human activity (anthropogenic nutrient load changes, coastal management, fisheries) on the marine ecosystem.

\section{OBJECTIVES}

The ECOSUPPORT work plan was built on the confidence of models' capacity to simulate the changing climate, and included the following aspects: (i) the assessment of predictive skills of the models by comparing observed and simulated past climate variability (i.e., quantification of model uncertainties) and analyzing causes of observed variations (e.g., Gustafsson et al. 2012; Meier et al. 2012; Niiranen et al. 2012), (ii) the performance of multi-model ensemble simulations of the marine ecosystem for 1850 2100 , forced by reconstructions of the past climate (e.g., Gustafsson et al. 2012; Ruoho-Airola et al. 2012) and various future greenhouse gas emission scenarios and airand river-borne nutrient load scenarios (ranging from a pessimistic business-as-usual to the most optimistic case) (e.g., Arheimer et al. 2012; Eilola et al. 2012; MacKenzie et al. 2012; Meier et al. 2012; Neumann et al. 2012), (iii) the analysis of projections for the future Baltic Sea ecosystem, using a probabilistic approach accounting for uncertainties caused by biases of regional and global climate models, lack of process description in state-of-the-art ecosystem models, unknown greenhouse gas emissions and nutrient loadings as well as natural variability (e.g., Arheimer et al. 2012; MacKenzie et al. 2012; Meier et al. 2012; Neumann et al. 2012; Niiranen et al. 2012), (iv) the assessment of climate change impacts on the marine biota,

\footnotetext{
${ }^{1}$ www.baltex-research.eu/ecosupport.
} 


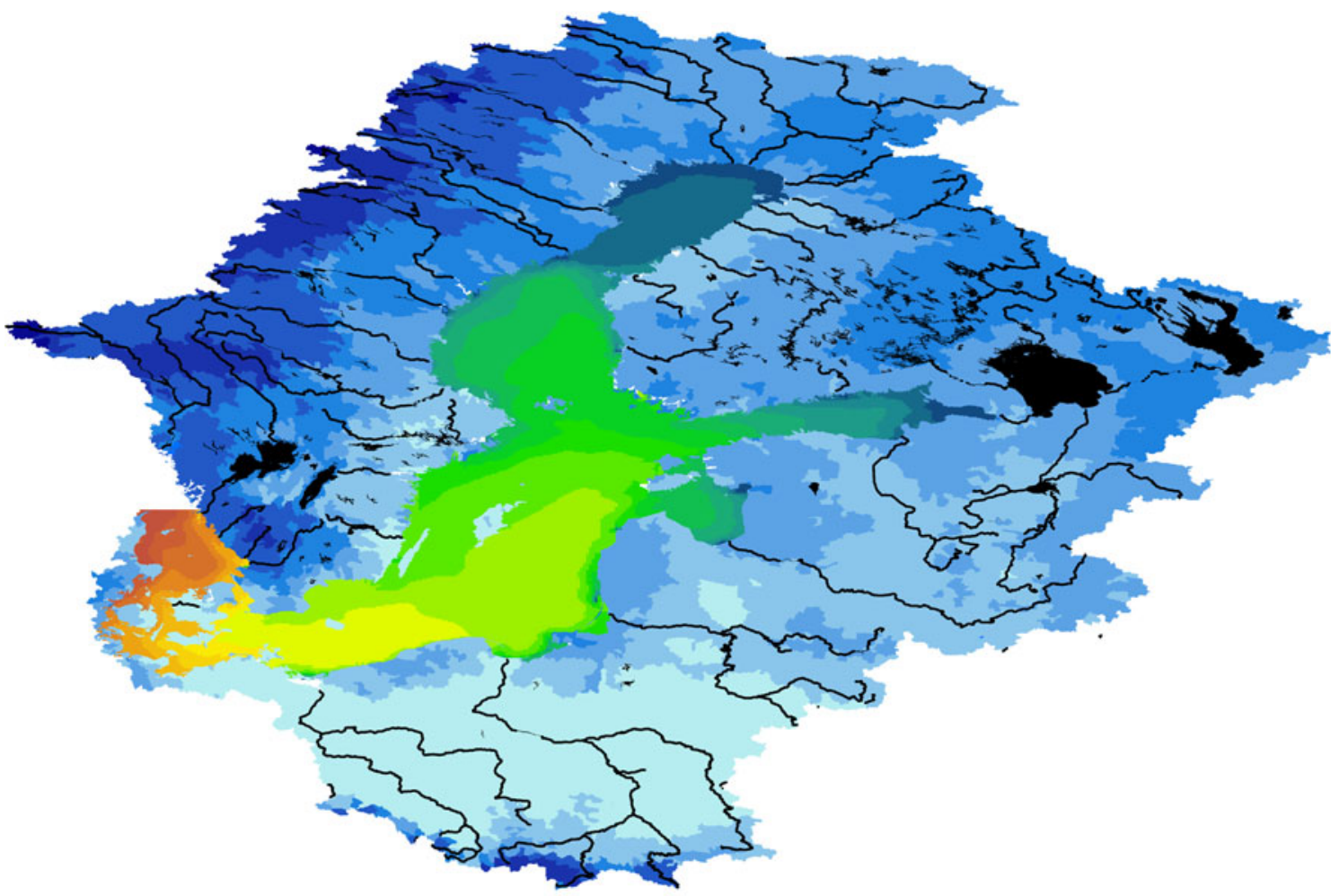

\section{Salinity}

\begin{tabular}{|c|c|c|c|}
\hline & $0.1-2.3$ & " & $7.8-8.6$ \\
\hline & $2.4-3.3$ & " & $8.7-10.2$ \\
\hline & $3.4-4.1$ & " & $10.3-12.1$ \\
\hline & $4.2-4.7$ & " & $12.2-14.3$ \\
\hline & $4.8-5.2$ & " & $14.4-16.4$ \\
\hline & $5.3-5.7$ & - & $16.5-18.5$ \\
\hline & $5.8-6.1$ & - & $18.6-20.9$ \\
\hline & $6.2-6.7$ & - & $21.0-23.9$ \\
\hline & $6.8-7.2$ & - & $24.0-29.3$ \\
\hline & $7.3-7.7$ & & \\
\hline
\end{tabular}

\section{Local runoff $[\mathrm{mm}]$}

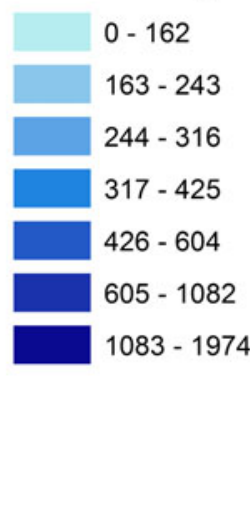

Fig. 1 Baltic Sea catchment area and climatological sea surface salinity 1961-2006 calculated with RCO-SCOBI

like effects of ocean acidification (e.g., Havenhand 2012), biodiversity and fish populations with focus on cod, sprat and herring (e.g., MacKenzie et al. 2012; Niiranen et al. 2012), (v) a socioeconomic impact assessment (e.g., Piwowarczyk et al. 2012), (vi) the generation of a freeaccess data base of scenario model results and tools to access the database with the help of a decision support system (DSS) ${ }^{2}$ and finally (vii) the dissemination of project results to stakeholders, decision makers and the public (see below).

\footnotetext{
${ }^{2}$ See www.baltex-research.eu/ecosuppport.
}

\section{METHODS}

Within ECOSUPPORT a hierarchy of existing state-of-theart sub-models of the Earth system was applied (Fig. 2). For dynamical downscaling, a high-resolution coupled atmosphere-ice-ocean-land surface model (the Rossby Centre Atmosphere Ocean model, RCAO), with lateral boundary data from global General Circulation Models (GCMs), was used to project the future climate of the Baltic Sea region (Meier et al. 2011a, 2012). The regional scenario simulations differ depending on the applied GCM at the lateral boundaries and depending on the utilized 
Fig. 2 Model hierarchy in ECOSUPPORT and work package (WP) structure (for details see text)

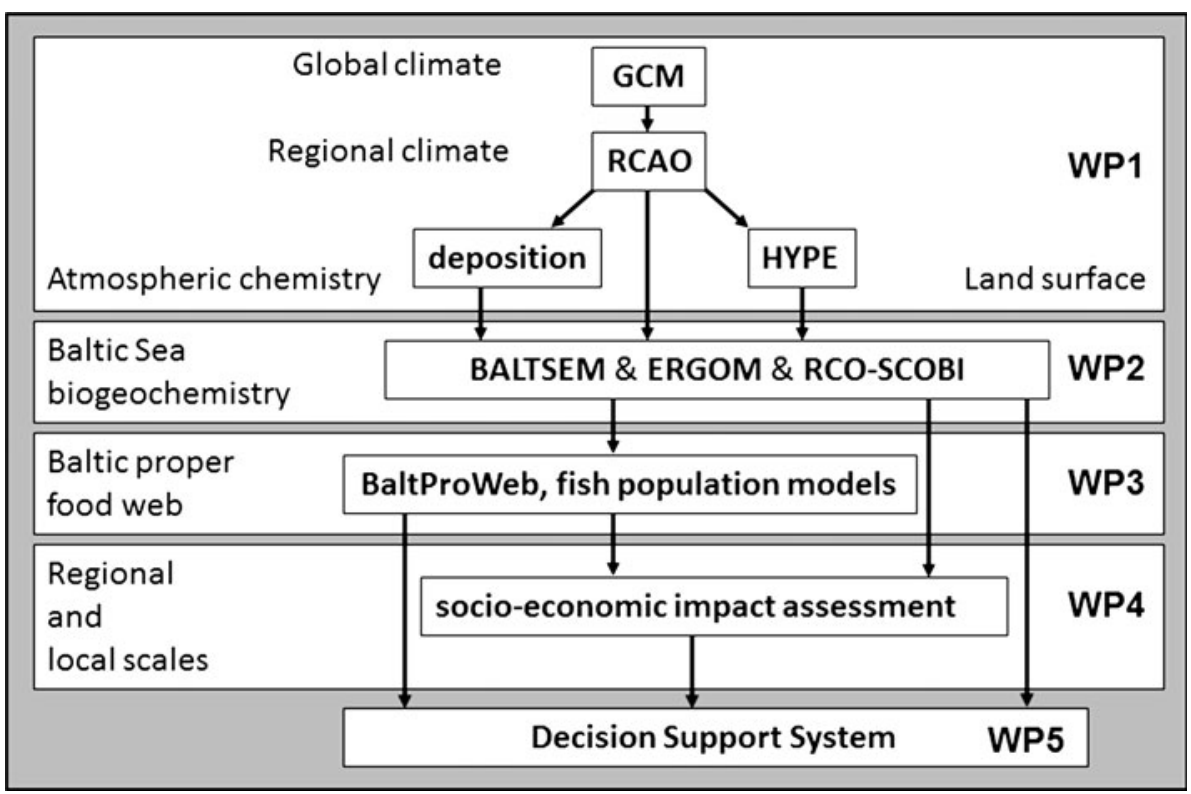

greenhouse gas and aerosol emission scenario. To calculate future river flow and river-borne nutrient loadings a new hydrological model (HYdrological Predictions for the Environment, HYPE) was developed and applied (Arheimer et al. 2012).

Furthermore, three state-of-the-art coupled physicalbiogeochemical models were used to calculate changing concentrations of nitrate, ammonium, phosphate, autotrophs, zooplankton, detritus and oxygen, i.e., BALTSEM, ERGOM and RCO-SCOBI (Meier et al. 2011b, 2012; Eilola et al. 2012; Neumann et al. 2012). Higher trophic levels were assessed with a food web model for the Baltic proper (Niiranen et al. 2012) and statistical fish population models (MacKenzie et al. 2012). Using model outputs from the three biogeochemical models, scenario simulations for the marine food web were performed. The ensemble approach applied to coupled climate-environmental modelling has never been utilized as comprehensive as in ECOSUPPORT before.

For three selected focus study sites, the Gulf of Finland, the Vistula Lagoon and the Polish coastal waters, assessments of the impact of climate change on the regional and local development were conducted, and the socioeconomic implications were assessed (Piwowarczyk et al. 2012).

The results from all scenario simulations were fed into a DSS, hosted by the public ECOSUPPORT webpage ${ }^{3}$ to support decision makers and stakeholders with a tool providing them with relevant and readily accessible information that will help to raise wider public awareness.

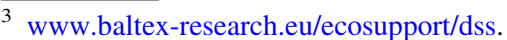

\section{SCIENTIFIC COMMUNICATION IN A GEODOME $^{\mathrm{TM}}$}

Another milestone of ECOSUPPORT is the development of a new dissemination technique, utilizing the GeoDome ${ }^{\mathrm{TM}}$. To satisfy the need for a more interactive environment, where scientists and policy makers can meet to discuss and compare possible outcomes of different measures and taken actions, a new form of scientific communication was developed, tested and evaluated during the project. By this technique, research data are projected onto a cupola-shaped screen inside an inflatable, enclosed dome (Andersson et al. 2010). The aim of using a visualization technique such as the GeoDome ${ }^{\mathrm{TM}}$, is both educational (processes behind eutrophication can be discussed) and scientific, showing ECOSUPPORT results in terms of scenarios for the future due to different nutrient loads in a changing climate.

The GeoDome ${ }^{\mathrm{TM}}$ was presented at various stakeholder conferences, and dedicated presentations were performed for University students, policy makers and scientists at specific project meetings, as well as politicians and governmental officers at the Government Offices of Sweden. The format had previously been shown to encourage discussion and enhance the understanding of scientific results (Neset et al. 2010), and it was also the experience of the ECOSUPPORT project that this kind of dissemination product is innovative and engaging, and promotes effective communication of scientific concepts to all sorts of audiences. Hence, it is well suited as an arena to provide background for decision making. The work with the GeoDome $^{\mathrm{TM}}$ was awarded the BONUS+ award 2011 for the best public activity or product (Fig. 3). 
Fig. 3 The GeoDome ${ }^{\mathrm{TM}}$ at the European Union Strategy for the Baltic Sea Region conference in Gdansk, 2011. From left to right Gabriella Lindholm, HELCOM Chair, Swedish Ministry of the Environment; Helén Andersson, ECOSUPPORT; Lena Ek,

Swedish Minister for the Environment; Patrik Wallman, ECOSUPPORT. (Photo: Tina Neset, Centre for Climate Science and Policy Research)

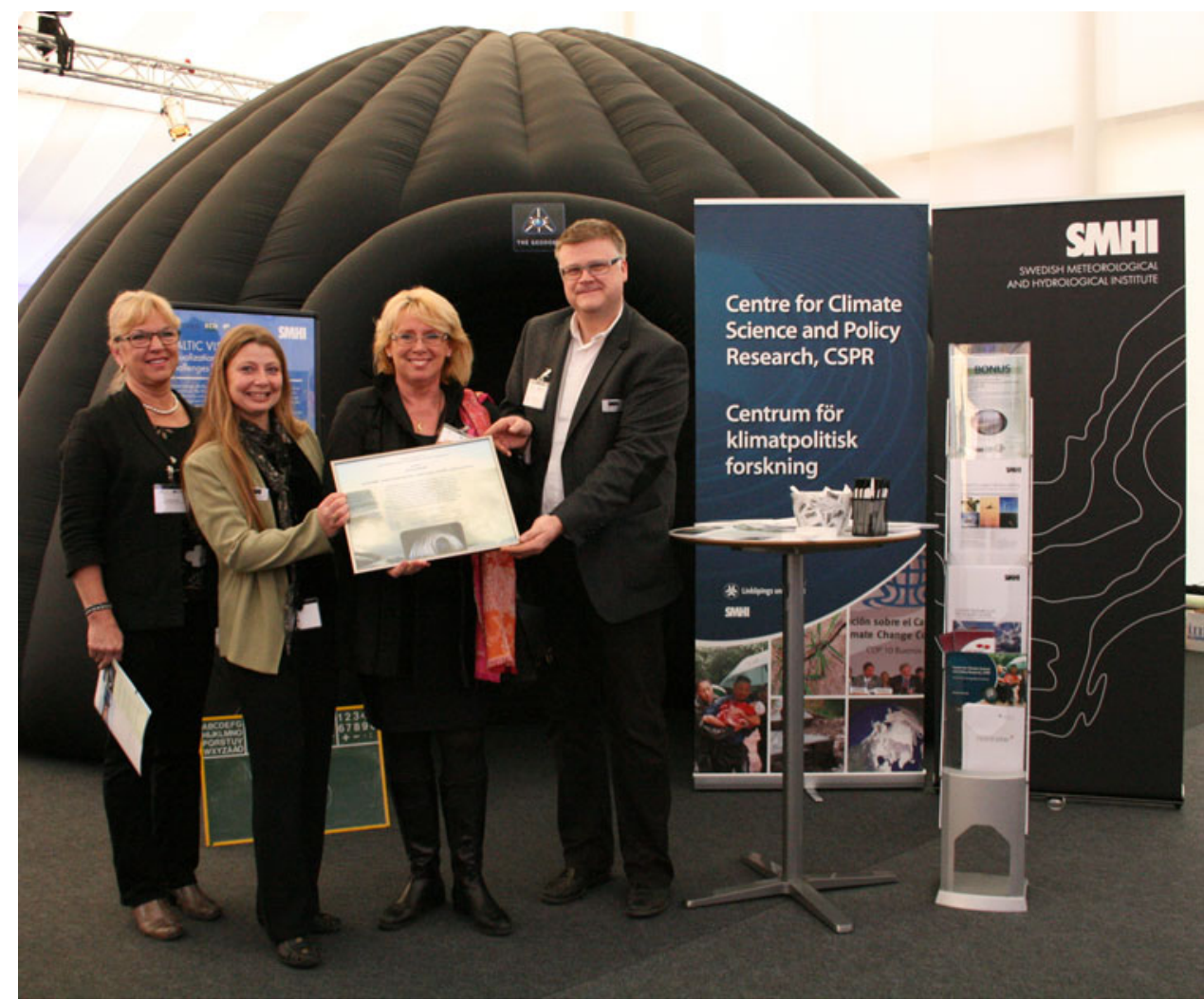

\section{KEY RESULTS}

The Baltic Sea models applied in ECOSUPPORT are capable of simulating past climate variations and eutrophication since 1850 , building confidence that the models are able to simulate future changes (e.g., Eilola et al. 2011; Gustafsson et al. 2012; Niiranen et al. 2012; Ruoho-Airola et al. 2012). In future climate, water temperatures are projected to increase and salinities are projected to decrease (due to the increased total freshwater supply), which is in accordance with earlier studies (e.g., Arheimer et al. 2012; Meier et al. 2012; Neumann et al. 2012). Despite the high uncertainties involved, which are due to model shortcomings and unknown future scenarios of external nutrient loads, a basic conclusion seems to be that climate change can be expected to reinforce oxygen depletion, to increase phytoplankton biomass, and to reduce water transparency and biodiversity (due to decreased salinity) (e.g., Eilola et al. 2012; Meier et al. 2011b, 2012; Neumann et al. 2012). Further, we found that in future climate, cod biomass may decrease and sprat biomass may increase assuming present day estimates of sustainable fishing (e.g., MacKenzie et al. 2012; Niiranen et al. 2012). However, all food web and fish population models indicate that the level of cod fishery is important for determining the cod stock size also in the future, independent of the climate scenario used. Although available data suggest that most species in the Baltic Sea will be robust to projected changes in $\mathrm{pH}$, the effects of acidification on the food web are difficult to estimate because results from food web modelling are not yet available (e.g., Havenhand 2012).

Although ECOSUPPORT was very successful and its results will be used to revise the BSAP, further research and dissemination is needed. Unfortunately, coastal stakeholders pay today still too little attention to adaptation and mitigation strategies (Piwowarczyk et al. 2012).

Acknowledgments ECOSUPPORT has received funding from the European Community's Seventh Framework Program (FP/20072013) under grant agreement no. 217246 made with BONUS, the joint Baltic Sea research and development program, and from national funding agencies in Denmark, Estonia, Finland, Germany, Poland, Russia and Sweden (see the research articles of this special issue). ECOSUPPORT was performed under the umbrella of the BALTEX (Baltic Sea Experiment) program. The support of the International BALTEX Secretariat for this special issue is greatly acknowledged. Last but not least, we would like to thank the guest editor, Marcus Reckermann, for his tremendous effort to organize this Special Issue, the maintenance of the ECOSUPPORT homepage and all help since the project start.

\section{REFERENCES}

Andersson, H.C., P. Wallman, and C. Donnely. 2010. Visualization of hydrological, physical and biogeochemical modelling if the Baltic Sea using a GeoDome ${ }^{\mathrm{TM}}$. SMHI Report Oceanography 105: 22. 
Arheimer, B., J. Dahné, and C. Donnelly. 2012. Climate change impact on riverine nutrient load and land-based remedial measures of the Baltic Sea Action Plan. AMBIO. doi:10.1007/ s13280-012-0323-0.

Backer, H., J.-M. Leppänen, A.C. Brusendorff, K. Forsius, M. Stankiewicz, J. Mehtonen, M. Pyhälä, M. Laamanen, et al. 2010. HELCOM Baltic Sea action plan-a regional programme of measures for the marine environment based on the ecosystem approach. Marine Pollution Bulletin 60: 642-649.

Eilola, K., B.G. Gustafson, I. Kuznetsov, H.E.M. Meier, and O.P. Savchuk. 2011. Evaluation of biogeochemical cycles in an ensemble of three state-of-the-art numerical models of the Baltic Sea. Journal of Marine Systems 88: 267-284.

Eilola, K., E. Almroth Rosell, C. Dieterich, F. Fransner, A. Höglund, and H.E.M. Meier. 2012. Nutrient transports and exchanges of nutrients between shallow regions and the open Baltic Sea: A model study in present and future climate. AMBIO. doi: 10.1007/s13280-012-0322-1.

Gustafsson, B.G., F. Schenk, T. Blenckner, K. Eilola, H.E.M. Meier, B. Müller-Karulis, T. Neumann, T. Ruoho-Airola, et al. 2012. Reconstructing the development of Baltic Sea eutrophication 1850-2006. AMBIO. doi:10.1007/s13280-012-0318-x.

Hansson, M., L. Andersson, and P. Axe. 2011. Areal extent and volume of anoxia and hypoxia in the Baltic Sea, 1960-2011. Report Oceanography no. 42. Norrköping, Sweden: SMHI.

Havenhand, J.N. 2012. How will ocean acidification affect Baltic Sea ecosystems? An assessment of plausible impacts on key functional groups. AMBIO. doi:10.1007/s13280-012-0326-x.

Leppäranta, M., and K. Myrberg. 2009. Physical oceanography of the Baltic Sea. Berlin: Springer.

MacKenzie, B.R., H.E.M. Meier, M. Lindegren, S. Neuenfeldt, M. Eero, T. Blenckner, M. Tomczak, and S. Niiranen. 2012. Impact of climate change on fish population dynamics in the Baltic Sea-a dynamical downscaling investigation. AMBIO. doi: 10.1007/s13280-012-0325-y.

Meier, H.E.M., A. Höglund, R. Döscher, H. Andersson, U. Löptien, and E. Kjellström. 2011a. Quality assessment of atmospheric surface fields over the Baltic Sea of an ensemble of regional climate model simulations with respect to ocean dynamics. Oceanologia 53: 193-227.

Meier, H.E.M., H.C. Andersson, K. Eilola, B.G. Gustafsson, I. Kuznetsov, B. Müller-Karulis, T. Neumann, and O.P. Savchuk. 2011b. Hypoxia in future climates-a model ensemble study for the Baltic Sea. Geophysical Research Letters 38: L24608. doi: 10.1029/2011GL049929.

Meier, H.E.M., B. Müller-Karulis, H.C. Andersson, C. Dieterich, K. Eilola, B.G. Gustafsson, A. Höglund, R. Hordoir, et al. 2012. Impact of climate change on ecological quality indicators and biogeochemical fluxes in the Baltic Sea-a multi-model ensemble study. AMBIO. doi:10.1007/s13280-012-0320-3.
Neset, T.-S., V. Wibeck, O. Uhrqvist, and J. Johansson. 2010. Visualizing climate change: The potential of dome presentations as a tool for climate communication. COMPUTER GRAPHICS Forum 12/2009 (Print) (ISSN 0167-7055) (EISSN 1467-8659).

Neumann, T., K. Eilola, B. Müller-Karulis, I. Kuznetsov, H.E.M. Meier, and O.P. Savchuk. 2012. Extremes of temperature, oxygen and blooms in the Baltic Sea in a changing climate. AMBIO. doi:10.1007/s13280-012-0321-2.

Niiranen, S., T. Blenckner, O. Hjerne, and M.T. Tomczak. 2012. Uncertainties in a Baltic Sea food-web model reveal challenges for future projections. AMBIO. doi:10.1007/s13280-012-0324-z.

Piwowarczyk, J., A. Hansson, M. Hjerpe, B. Chubarenko, and K. Karmanov. 2012. Climate change in the Baltic Sea region: A cross-country analysis of institutional stakeholder perceptions. AMBIO. doi:10.1007/s13280-012-0327-9.

Ruoho-Airola, T., K. Eilola, O.P. Savchuk, M. Parviainen, and V. Tarvainen. 2012. Atmospheric nutrient input to the Baltic Sea from 1850-2006: A reconstruction from modeling results and historical data. AMBIO. doi:10.1007/s13280-012-0319-9.

Wulff, F., O.P. Savchuk, A. Sokolov, and C. Humborg. 2007. Management options and effects on a marine ecosystem: assessing the future of the Baltic. AMBIO 36: 243-249.

\section{AUTHOR BIOGRAPHIES}

H. E. Markus Meier $(\bowtie)$ is an adjunct professor at Stockholm University and head of the Oceanographic Research Unit at the Swedish Meteorological and Hydrological Institute (SMHI). His current research interests focus on the analysis of climate variability and the impact of climate change on the physics and biogeochemical cycles in the Baltic Sea, North Sea and Arctic Ocean.

Address: Swedish Meteorological and Hydrological Institute, 60176 Norrköping, Sweden.

e-mail: markus.meier@smhi.se

Helén C. Andersson is a researcher and research coordinator at the Swedish Meteorological and Hydrological Institute. She is interested in physical and biogeochemical dynamics of the sea, with special emphasis on water quality and impact of climate variability.

Address: Swedish Meteorological and Hydrological Institute, 60176 Norrköping, Sweden.

e-mail: helen.andersson@smhi.se

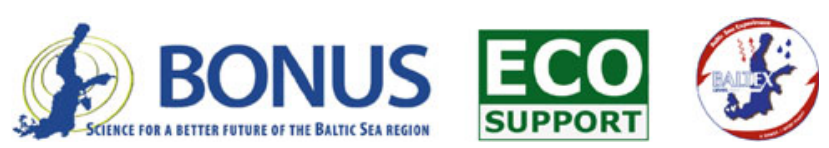

